\title{
Modelling of oedometer tests on pellet-powder bentonite mixtures to support mock-up test analysis
}

\author{
Arisleidy Mesa Alcantara ${ }^{1, *}$, Nadia Mokni $^{2}$, Enrique Romero $^{1}$, and Sebastià Olivella ${ }^{1}$ \\ ${ }^{1}$ Universitat Politècnica de Catalunya, 08034 Barcelona, Spain \\ ${ }^{2}$ Institut de Radioprotection et de Sûreté Nucléaire (IRSN), 92260 Fontenay-aux-Roses, France
}

\begin{abstract}
Bentonite mixtures of MX-80 (80\% of high-density pellets and $20 \%$ of bentonite powder on a mass basis) have been recently proposed as a candidate material for sealing deep geological disposals of high-level radioactive waste. A loading/unloading oedometer test at constant water content has been performed on this mixture, which has been modelled using the finite element Code_Bright. The constitutive model used to represent the mechanical response is the Barcelona Expansive Model (BExM), since a multimodal pore size distribution characterises the pore network of the mixture. During compression at constant water content, an increase in the degree of saturation and a consequent reduction of suction is induced. Consequently, two competing effects occur at different pore-size scales: (a) compression due to mean net stress increase; and (b) expansion on induced suction reduction that mainly affects the micro-porosity level inside aggregates. A sensitivity analysis has been performed to explore these effects, in which the elastic compressibility parameter at the micro-porosity scale for changes in mean effective stress plays an important role.
\end{abstract}

\section{Introduction}

Heterogeneous mixtures of high-density bentonite have been suggested as a suitable sealing material for nuclear disposals of high-level radioactive waste. These mixtures display a high swelling capacity, low permeability and high radionuclide migration retardation properties $[1,2]$. Furthermore, bentonite-based mixtures can efficiently decrease the gaps between the rock and the seal due to operational advantages in terms of emplacement [3-5].

The French Institute for Radiological Protection and Nuclear Safety (IRSN) has launched VSEAL project, which relies on a series of in situ experiments performed in IRSN's Underground Research Laboratory (Tournemire, France). These experiments aim at studying the long-term hydration process of an engineered barrier composed of a binary mixture of MX80 bentonite, as well as the impact of gas migration at different hydraulic states. The binary mixture is constituted by high-density bentonite pellets ( $80 \%$ mass ratio) and bentonite powder. Based on the design of the in situ experiments, a laboratory mock-up test (1/10th scale) has also been launched. The small-scale mock-up test $(100 \mathrm{~mm}$ in diameter and $350 \mathrm{~mm}$ high) presents independent top (fast injection) and radial (slow injection) water systems to mimic real hydraulic conditions. Within this context, several loading/unloading oedometer tests at different hydraulic states have been carried out to support the mock-up test and understand the mechanical response of the mixture.
This paper focuses on numerical modelling using the finite element program Code_Bright [6] of a specific loading/unloading oedometer test performed under constant water content conditions. In particular, the Barcelona Expansive Model (BExM) [7,8] has been used to describe the mechanical behaviour of the double porosity mixture (micro and macro-porosity). BExM allows the distinction of the deformational response of these two porosity levels, which are affected by mean net stress and suction changes (macro-porosity) and mean effective stress changes (micro-porosity). Therefore, on loading at constant water content, two competing effects at different scales may occur (compression response on stress increase, and expansion on suction decrease associated with the degree of saturation increase). Within this context, the elastic stiffness parameter at the microporosity level for changes in mean effective stress displays an essential role by inducing the expansion of the micro-pore volume on compression and reducing the macro-pore volume. A sensitivity analysis is performed in the paper to investigate the effect of this microporosity elastic stiffness parameter on the global mechanical response of the mixture.

\section{Material description and oedometer test}

The investigated material is MX-80 bentonite mixture with a mass base proportion of $80 \%$ high-density pellets and $20 \%$ powder. MX-80 bentonite presents a high 
montmorillonite content (80\%), liquid limit 420 - 560\%, plastic limit $62 \%$, and density of particles $2.77 \mathrm{Mg} / \mathrm{m}^{3}$ [9]. High-density bentonite pellets (approximately $7 \mathrm{~mm}$ in diameter) have been produced by compaction to a dry density $\rho_{d}=1.99 \mathrm{Mg} / \mathrm{m}^{3}$. Bentonite powder has been fabricated by crushing pellets. The dry density of the powder is around $1.10 \mathrm{Mg} / \mathrm{m}^{3}$. The mixture has been prepared at a dry density $\rho_{d}=1.49 \mathrm{Mg} / \mathrm{m}^{3}$ and water content $w=8.5 \%$ to $9.8 \%$ corresponding to a void ratio $e=0.859$ (porosity $\phi=0.462$ ) and degree of saturation $\mathrm{Sr}=0.27$ to 0.32 . Figure 1 presents the mixture and the two components (pellets and powder).

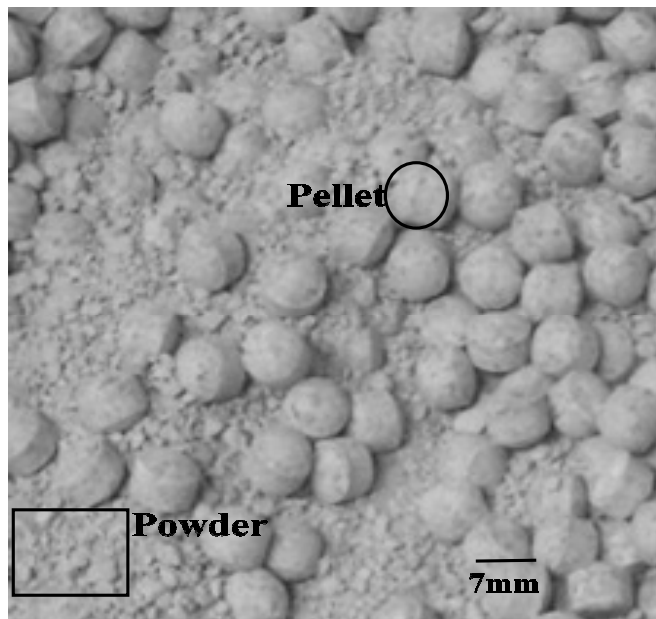

Fig.1. MX-80 bentonite mixture of pellets and powder.

The mixture is characterised by a multi-porosity network that evolves during the mechanical test (loading/unloading). Figure 2 shows the pore size distributions (PSDs) obtained by mercury intrusion porosimetry of the pellet and the powder at their initial state. Bimodal distributions are observed for both components. The pellet displays dominant modes of entrance pore size at approximately $20 \mathrm{~nm}$ (micro-pores inside aggregates) and between $10 \mu \mathrm{m}$ and $20 \mu \mathrm{m}$ (macro-pores between aggregates and fissures) [3,10,11]. The powder shows two dominant pore size families at 20 $\mathrm{nm}$ (inside aggregates) and between $170 \mu \mathrm{m}$ and $190 \mu \mathrm{m}$ (between aggregates). Consequently, the mixture displays a multi-modal PSD with micro-porosity (intraaggregate pores in powder and pellets), macro-porosity (inter-aggregate pores in powder and pellets), and larger macro-pores between the shielding skeleton of the pellets and the powder (inter-grain porosity considered hereafter as part of the macro-porosity). These PSDs are used to estimate the initial micro-porosity $\phi^{\text {micro }}$ $=0.193$ and the macro-porosity $\phi^{\text {macro }}=\phi-\phi^{\text {micro }}$ $=0.269$.

The loading/unloading paths have been performed with the oedometer cell and lever mechanism presented in Figure 3. The diameter of the ring is $50 \mathrm{~mm}$ with a height of $20 \mathrm{~mm}$. The cell avoids water loss while keeping air pressure under atmospheric conditions. The test has been carried out with a mixture at a constant water content of around $9.8 \%$ and with an initial total suction around $85 \mathrm{MPa}$ measured with a dew-point mirror psychrometer. Table 1 shows the stress paths followed on step loading/unloading, as well as the elapsed time on each step. The elapsed time is required for the modelling stage.

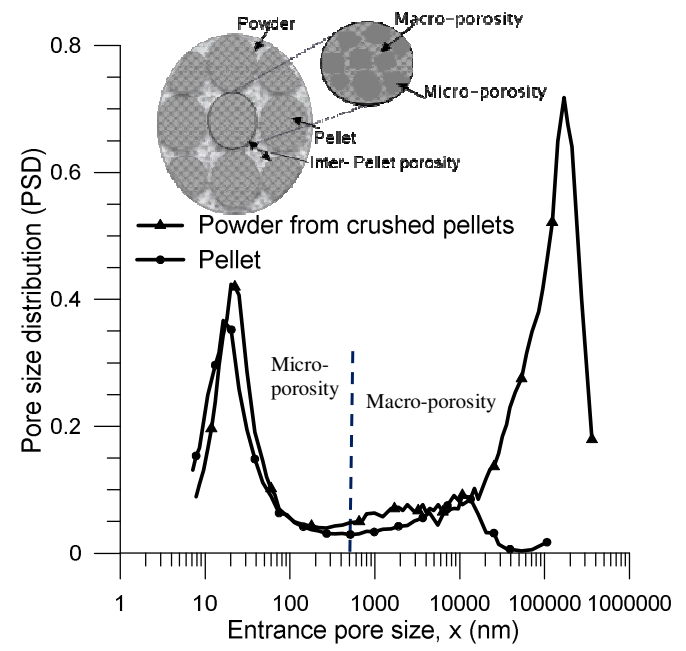

Fig.2. PSD functions of the pellet and the powder at their initial state.

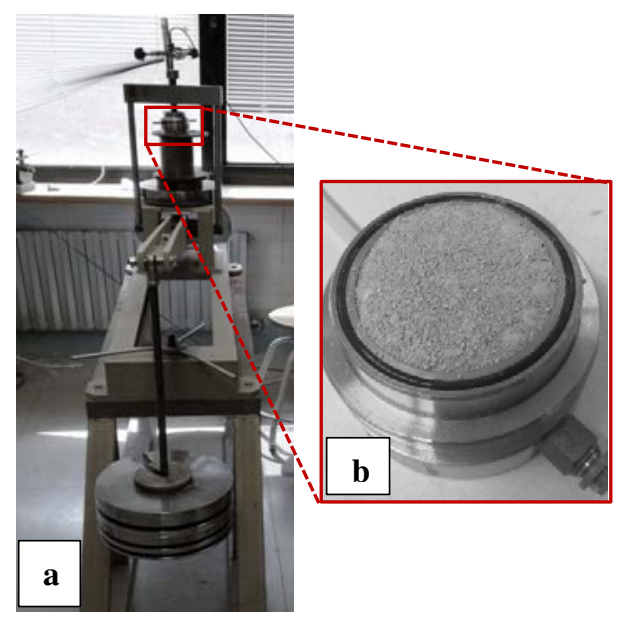

Fig. 3. (a) Setup of the oedometer test in a lever system. (b) Tested sample inside the metallic ring with O-ring to prevent water loss.

Table 1. Stress paths followed in oedometer cell.

\begin{tabular}{|c|c|c|}
\hline & \multicolumn{2}{|c|}{ Loading/unloading steps } \\
\hline & $\begin{array}{c}\text { Vertical } \\
\text { stress (MPa) }\end{array}$ & $\begin{array}{c}\text { Time } \\
\text { (minutes) }\end{array}$ \\
\hline \multirow{8}{*}{ 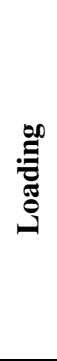 } & 0.05 & $0-12$ \\
\hline & 0.1 & $12-19$ \\
\hline & 0.2 & $19-30$ \\
\hline & 0.4 & $30-69$ \\
\hline & 0.8 & $69-85$ \\
\hline & 1.6 & $85-103$ \\
\hline & 3.2 & $103-122$ \\
\hline & 5 & $122-129$ \\
\hline \multirow{5}{*}{ 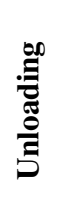 } & 3.5 & $129-177$ \\
\hline & 1.7 & $177-225$ \\
\hline & 0.8 & $225-251$ \\
\hline & 0.2 & $251-272$ \\
\hline & 0.1 & $272-334$ \\
\hline
\end{tabular}


Figure 4 plots the vertical stress steps applied against the elapsed time. The evolution of (total) porosity at the end of each step is also included. These time-evolution plots will be used when plotting the numerical results. More conventional compressibility curves on loading/unloading and in terms of void ratio are shown in Figure 5. A pre-consolidation (vertical) stress under partial saturation slightly higher than $1 \mathrm{MPa}$ can be obtained from the plotted results

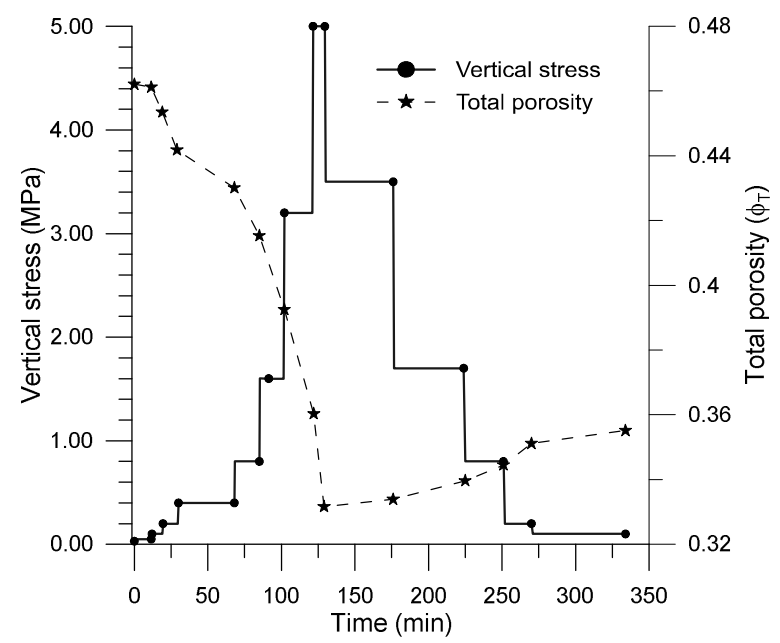

Fig. 4. Time evolution of vertical stress and total porosity.

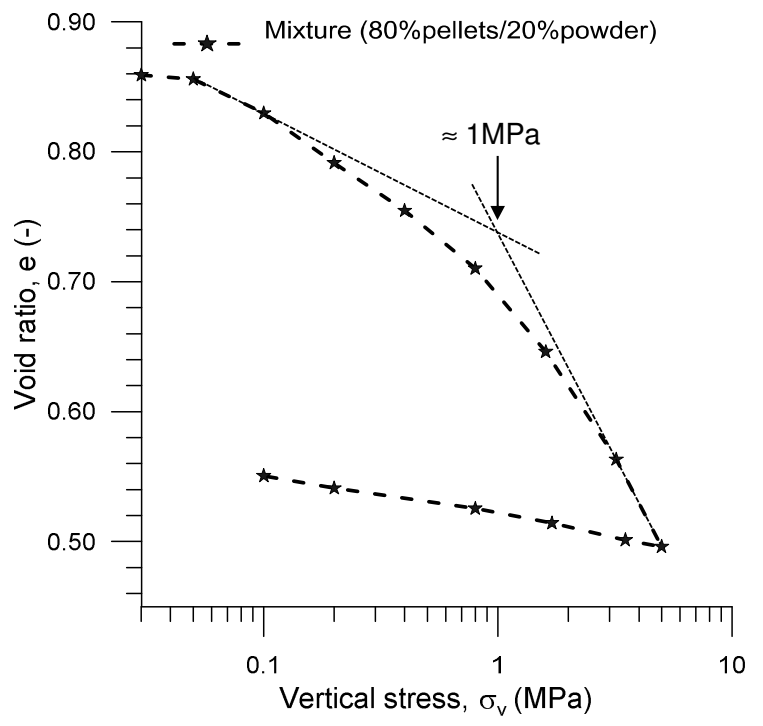

Fig. 5. Compressibility curves on loading/unloading.

\section{Numerical modelling of oedometer test}

\subsection{Some insight on Barcelona Expansive Model (BExM)}

The Barcelona Expansive Model (BExM) [7] is a mechanical constitutive model particularly suitable for geomaterials with bimodal pore-size distribution (i.e., macro and micro-porosity).

The model assumes that for the macrostructural level, both elastic and plastic strains can develop as a result of mean net stress and suction changes. The behaviour of the macrostructural level is defined by the Barcelona Basic Model (BBM) [12]. A fundamental assumption of the framework is that the microstructural behaviour is independent of the macrostructural state and only responds to changes in suction and stresses at the local microstructural level.

The increment of the total elastic volumetric strain of the medium is computed as the sum of the increments of macro and micro elastic deformations [7]:

$$
d \varepsilon_{v}^{e}=d \varepsilon_{v}^{e M a c r o}+d \varepsilon_{v}^{\text {emicro }}
$$

where $d \varepsilon_{v}^{e}$ is the increment of the volumetric elastic strain; $d \varepsilon_{v}^{e \text { Macro }}$ the increment of the volumetric elastic strain related to changes in the macro-porosity; and $d \varepsilon_{v}^{e M i c r o}$ the increment of the volumetric elastic strain related to changes in the micro-porosity.

The increment of the macrostructural volumetric elastic strain $d \varepsilon_{v}^{e \text { Macro }}$ is expressed as a function of the increments of mean net stress and suction as

$$
d \varepsilon_{v}^{\text {eMacro }}=\frac{\kappa^{\text {Macro }} d p}{\left(1+e_{\text {Macro }}\right) p}+\frac{\kappa_{s}{ }^{\text {Macro }} d\left(s+p_{a t m}\right)}{\left(1+e_{\text {Macro }}\right)\left(s+p_{a t m}\right)}
$$

where $p$ refers to the mean net stress, $s$ is the (total) suction, $p_{a t m}$ the atmospheric pressure, $e_{\text {Macro }}$ the macrostructural void ratio, $\kappa^{\text {Macro }}$ the elastic compressibility at the macro-porosity level for changes in mean stress, and $\kappa_{s}$ Macro the elastic macro compressibility for changes in suction. The initial $e_{\text {Macro }}$ can be estimated based on the (total) initial void ratio $e$ and the initial microstructural void ratio $e_{\text {Micro }}$ which is determined based on the initial microporosity $\phi^{\text {Micro }}$ [13].

The increment of the microstructural strain $d \varepsilon_{v}^{e \text { Micro }}$ is assumed to be volumetric, nonlinear elastic and proportional to the increment of the mean effective stress as

$$
d \varepsilon_{v}^{e \text { Micro }}=\frac{\kappa^{\text {Micro }} d(p+s)}{\left(1+e_{\text {Micro }}\right)(p+s)}
$$

where $(p+s)$ is the mean effective stress, $e_{\text {Micro }}$ the microstructural void ratio, and $\kappa^{\text {Micro the elastic }}$ compressibility at the micro level for changes in mean effective stress.

The parameters of the mechanical model and their values are summarised in Table 2. As observed, BExM involves a number of parameters associated with both elastic and plastic behaviour. Some parameters have been obtained from experimental results on the mixture, such as the saturated elastoplastic compressibility parameter $\lambda(0)$ (in terms of void ratio), and the saturated pre-consolidation (yield) stress $p_{0}^{*}$ [13]. Parameters not directly obtained from experimental results were taken from [14].

However, the emphasis has been placed on the previously described elastic volumetric behaviour. As will be later discussed, the modelled response is highly sensitive to the elastic compressibility parameter at the micro-porosity scale $\kappa^{\text {Micro }}$. 
Table 2. Mechanical parameters of BExM.

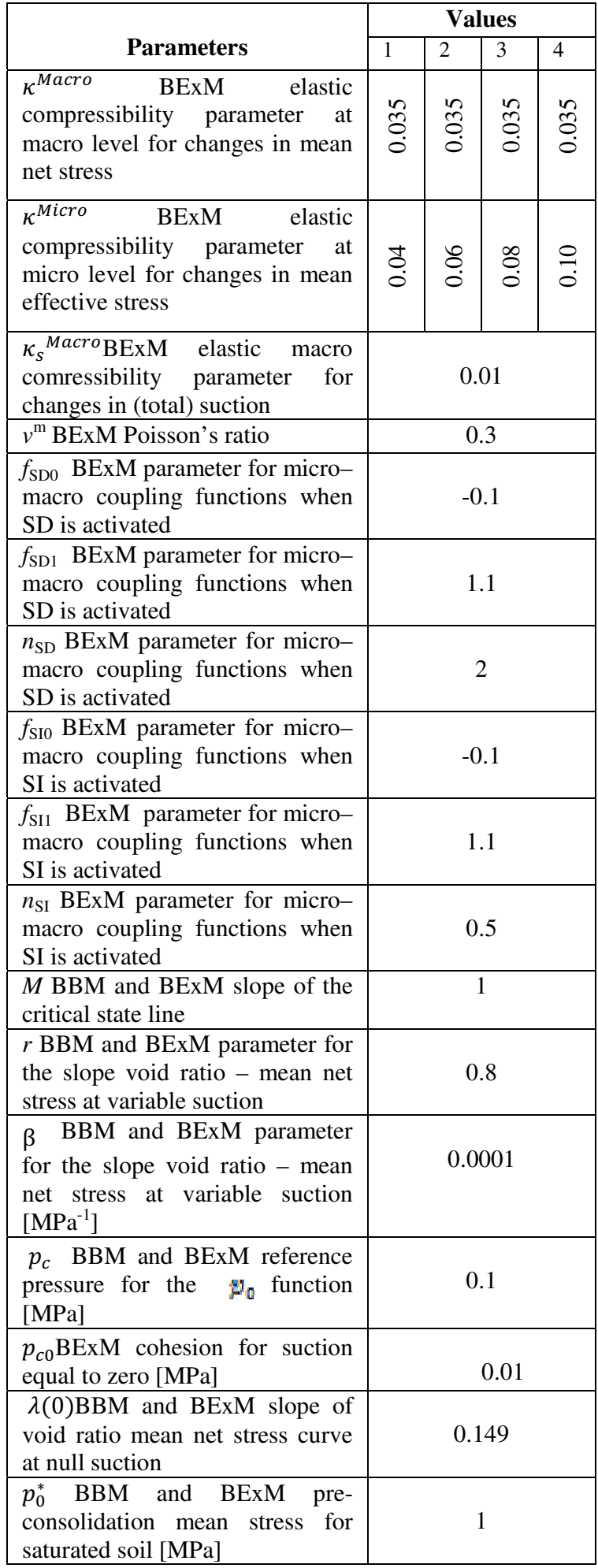

Regarding the hydraulic behaviour, the van Genuchten equation [15] has been used to describe the water retention curve of the mixture

$$
S_{e}=\left(\frac{S_{r}-S_{r l}}{S_{l s}-S_{r l}}\right)=\left(1+\left(\frac{\mathrm{s}}{\mathrm{P}}\right)^{\frac{\lambda}{1-\lambda}}\right)^{-\lambda}
$$

where $S_{\mathrm{e}}$ is the effective degree of saturation, $S_{\mathrm{r}}$ the degree of saturation, $S_{r l}$ the residual degree of saturation,
$S_{\mathrm{ls}}$ the maximum degree of saturation under saturated conditions, and $P$ and $\lambda$ are material parameters. The water retention curve will be used to compute the changes in (total) suction during loading/unloading, based on $S_{\mathrm{r}}$ changes at constant water content induced on compression (loading) and expansion (unloading).

The hydraulic behaviour in BExM is complemented with an equation for the intrinsic permeability evolution, which is an exponential function of the macro-porosity defined as

$$
k=k_{0} \exp \left[b\left(\phi^{\text {macro }}-\phi_{0}^{\text {macro }}\right)\right]
$$

where $\phi^{\text {Macro }}$ is the macro-porosity; $b$ a parameter and $k_{0}$ the reference intrinsic permeability at a reference macroporosity $\phi_{0}^{\text {Macro }}$ The saturated permeability was measured in the laboratory, and a value of $k_{0}=1.17 \times 10^{-20} \mathrm{~m}^{2}$ for $\phi_{0}^{\text {Macro }}=0.269$ was considered by [6].

The dependency of liquid relative permeability on the degree of saturation is expressed as

$$
k_{r l}=\mathrm{S}_{\mathrm{e}}^{\mathrm{n}}
$$

where $n$ is a material parameter, and $S_{\mathrm{e}}$ the effective degree of saturation previously defined in equation (4).

The hydraulic parameters used in the simulations are summarised in Table 3.

Table 3. Hydraulic parameters of BExM.

\begin{tabular}{|l|c|}
\hline \multicolumn{1}{|c|}{ Parameters } & Values \\
\hline van Genuchten water retention parameters $[15]$ \\
\hline$P[\mathrm{MPa}]$ & 10 \\
\hline$\lambda$ & 0.35 \\
\hline$S_{\mathrm{rl}}$ & 0 \\
\hline$S_{\mathrm{ls}}$ & 1 \\
\hline \multicolumn{2}{|c|}{ Intrinsic permeability } \\
\hline$k_{0}\left[\mathrm{~m}^{2}\right]$ & $1.17 \times 10^{-20}$ \\
\hline$\phi_{0}^{\text {Macro }}$ & 0.269 \\
\hline $\mathrm{b}$ & 1 \\
\hline \multicolumn{2}{|c|}{ Relative permeability } \\
\hline$n$ & 3 \\
\hline$S_{r l}$ & 0 \\
\hline$S_{l s}$ & 1 \\
\hline
\end{tabular}

\subsection{Geometry and boundary conditions. Simulations performed}

Figure 6 a shows the model geometry with a plane of symmetry. Figure $6 \mathrm{~b}$ displays the boundary conditions, in which horizontal displacements are restricted. The model is applied under plane strain conditions with normal (out-of-plane direction) displacements not allowed. 
Four 2D simulations are performed considering different values of $\kappa^{\text {micro }}$ compressibility $(0.04,0.06$, 0.08 , and 0.10 , as indicated in Table 2).
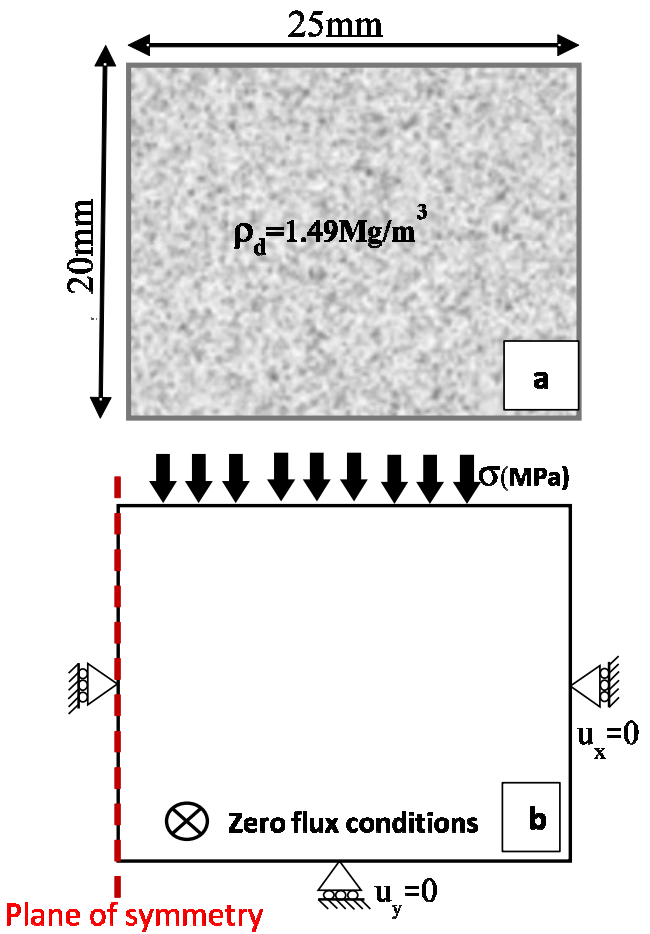

]Fig. 6. (a) Model geometry under plane strain conditions. (b) Mechanical and hydraulic boundary conditions.

\section{Results and interpretation}

Figure 7 shows the measured vertical (net) stress-void ratio relationship together with the modelling results for different values of $\kappa^{\text {micro }}$ (Table 2). As observed, small changes in this parameter affect the simulated deformation response of the mixture. The model prediction for $\kappa^{\text {micro }}=0.08$ appears to follow the experimental results satisfactorily.

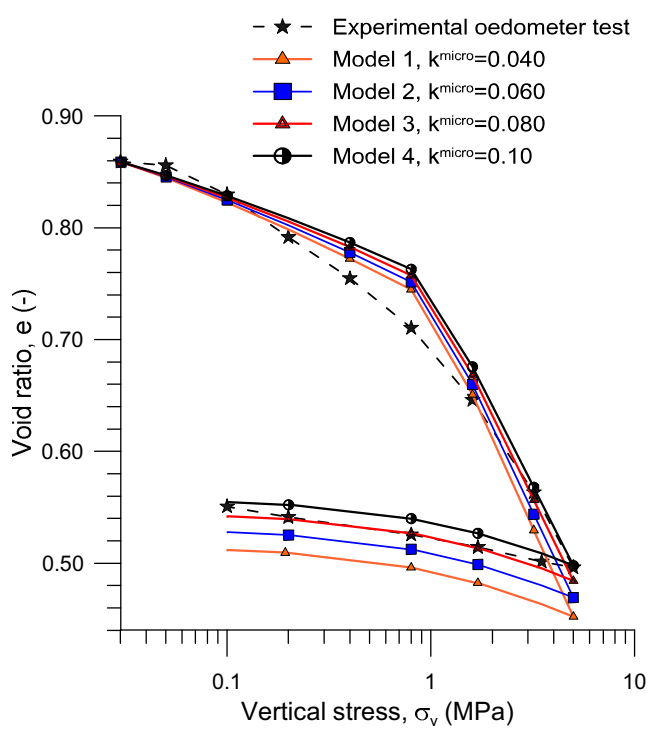

Fig. 7. Evolution of void ratio against axial stress. Experimental and modelling results.
Figure 8 displays the time evolution of the simulated degrees of saturation for the different loading/unloading steps and the different $\boldsymbol{K}^{\text {micro }}$ values. Loading to vertical stress of $5 \mathrm{MPa}$ induces an increase in the degree of saturation to $0.53-0.59$, while unloading to $0.1 \mathrm{MPa}$ generates a decrease up to $0.48-0.52$.

Figure 9 plots the time evolution of the computed changes in (total) suction associated with the changes in the degrees of saturation. On loading to vertical stress of $5 \mathrm{MPa}$, the suction reduces to around $22-28 \mathrm{MPa}$ ( $s=85 \mathrm{MPa}$ is the value at the initial state). On unloading to vertical stress $0.1 \mathrm{MPa}$, the suction reaches values around 30 - $46 \mathrm{MPa}$.

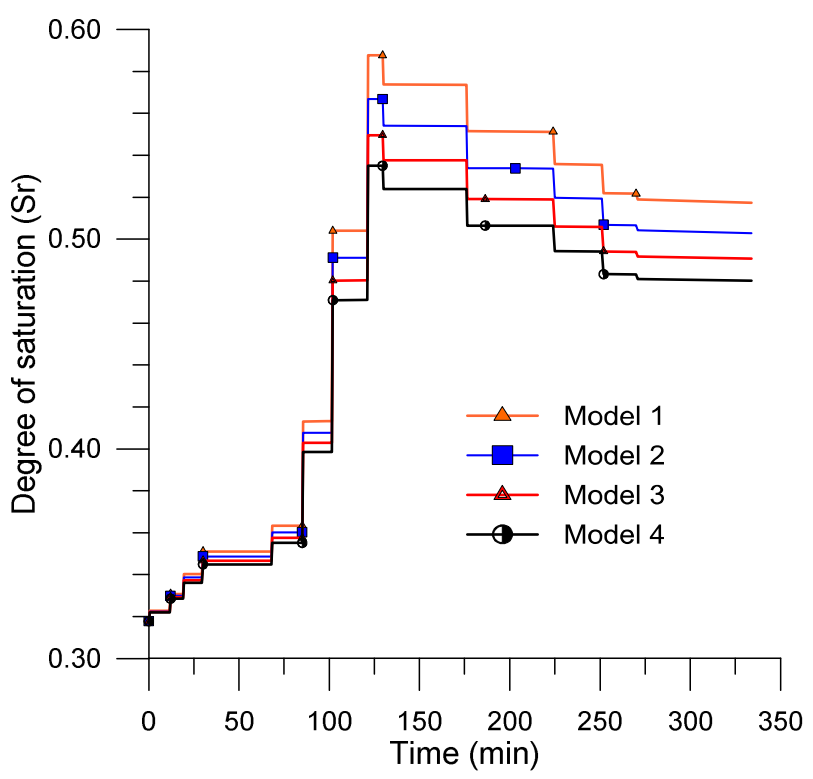

Fig. 8. Evolution of the degree of saturation as a function of time.

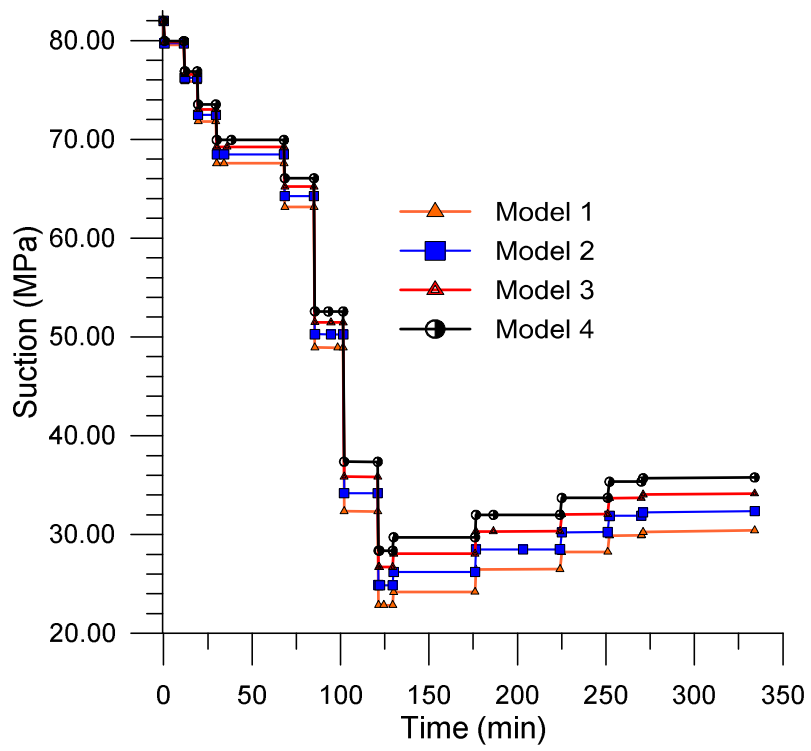

Fig. 9. Evolution of (total) suction as a function of time.

Figure 10 plots the modelled time evolutions of both total and micro porosities. The total porosity decreases inducing the increase of the degree of saturation and the decrease of suction (Figures 8 and 9). For $\kappa^{\text {minto }}=0.08$, the total porosity decreases to 0.33 at $5 \mathrm{MPa}$ starting 
from $\phi=0.462$ at the initial state. Interestingly, this decrease in total porosity on loading is accompanied by an increase in micro-porosity. In fact, two competing effects are occurring at the microstructural level. The increase in vertical stress tends to induce compression in the micropore volume, while (total) suction decrease leads to aggregate swelling and the corresponding increase in micro-porosity. It seems that $\kappa^{\text {micro }}$ plays a fundamental role since lower values reduce aggregate swelling and allow more compression of the macropores and the associated decrease in total porosity.

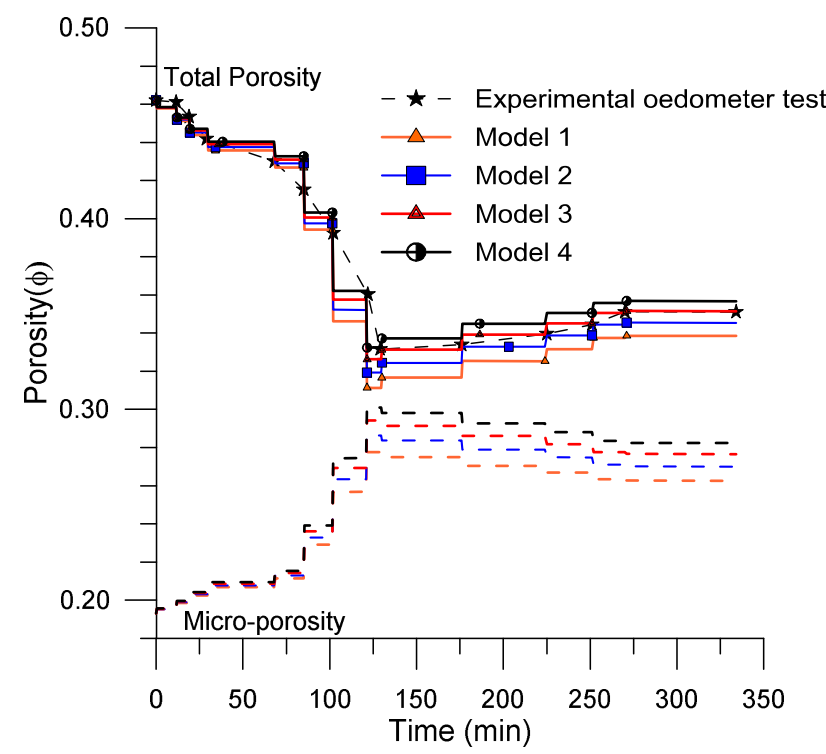

Fig. 10. Evolution of total and micro porosities as a function of time. Experimental and modelling results.

\section{Concluding remarks}

This paper presents experimental and modelling results of an oedometer test performed under constant water content conditions on a binary mixture of MX-80 (bentonite pellets and powder). The study addresses the effect of the micro-porosity compressibility $\kappa^{\text {micro }}$ on the global volume change behaviour of the mixture. Modelling results show that total porosity decreases inducing the increase of the degree of saturation and the decrease of suction. The sensitivity analysis demonstrates that changing values of $\kappa^{\text {micro }}$ affects the mechanical behaviour of the binary mixture significantly. For lower values of $\kappa^{\text {micro }}$, the material shows larger compressibility resulting in a higher decrease in total porosity. These results show how crucial it is to choose a reliable value when modelling experimental mock-up tests.

\section{Acknowledgements}

The authors wish to acknowledge the financial support of 'Institut de Radioprotection et de Sûreté Nucléaire' IRSN (France) through a $\mathrm{PhD}$ collaboration agreement with CIMNE (Spain) within the context of the VSEAL Project 'Long-term performance of vertical sealing systems and impact of gas migration' (2016-2020).

\section{References}

1. M. V. Villar and A. Lloret, Appl. Clay Sci. 39, 38 (2008).

2. R. N. Yong, P. Boonsinsuk, and G. Wong, Can. Geotech. J. 23, (1986).

3. E. E. Alonso, E. Romero, and C. Hoffmann, Géotechnique 61, 329 (2011).

4. A. Gens, M. Sánchez, B. Valleján, C. Imbert, M. V. Villar, and M. Van Geet, Géotechnique 61, 367 (2011).

5. A. Molinero Guerra, N. Mokni, Y.-J. Cui, A. M. Tang, P. Delage, P. Aimedieu, F. Bernier, and M. Bornert, (2018).

6. S. Olivella, A. Gens, J. Carrera Ramírez, and E. Alonso, Eng. Comput. 13, 87 (1996).

7. E. E. Alonso, J. Vaunat, and A. Gens, Eng. Geol. 54, 173 (1999).

8. M. Sanchez, A. Gens, L. do Nascimento Guimaraes, and S. Olivella, Int. J. Numer. Anal. METHODS Geomech. Int. J. Numer. Anal. Meth. Geomech 29, 751 (2005).

9. S. Saba, J.-D. Barnichon, Y.-J. Cui, A. M. Tang, and P. Delage, J. Rock Mech. Geotech. Eng. 6, 126 (2014).

10. E. Romero, G. Della Vecchia, and C. Jommi, Géotechnique 61, 313 (2011).

11. E. Romero, Eng. Geol. 165, 3 (2013).

12. E. E. Alonso, A. Gens, and A. Josa, Géotechnique 40, 405 (1990).

13. A. Mesa-Alcantara, Hydro-Mechanical Behaviour of Binary Pelletized Mixtures of Bentonite and Impact of Gas Migration., Universitat Politècnica de Catalunya, n.d.

14. E. Toprak, S. Olivella, and X. Pintado, Environ. Geotech. 1 (2018).

15. M. T. van Genuchten., Soil Sci. Soc. Am. J. J. 44, 892 (1980). 